\title{
Estudo sobre o empoderamento feminino através de comunidades de tecnologia
}

\author{
Sandyara B. Doro Peres ${ }^{1}$, Eduardo H. Gomes ${ }^{1}$ \\ ${ }^{1}$ Instituto Federal de Educação, Ciência e Tecnologia São Paulo (IFSP) \\ Caixa Postal 11.533-160 - Cubatão - SP - Brasil
}

\begin{abstract}
Women have been part of programming languages's history since before the first computer's appearance. However, this historical context did not prevent the decreasing number of women in the technology area. The problems of this decrease may be linked to the gender stereotype, the absence incentive since childhood, among other factors. This article aims to present the results of a survey and possible indicators of female empowerment extracted from programming languages technological communities. Thus, this article expectations is providing a greater incentive for women to join the technology area.
\end{abstract}

Resumo. As mulheres estão inseridas na história das linguagens de programação desde antes do surgimento do primeiro computador. Porém, esse contexto histórico não impediu o número de mulheres inseridas na área de tecnologia de diminuir. Os problemas dessa diminuição podem estar ligados ao estereótipo de gênero e a ausência de incentivo desde a infância. Este trabalho tem por objetivo apresentar os resultados de um levantamento e possiveis indicadores de empoderamento feminino extraidos de comunidades tecnológicas de linguagens de programação. Assim, espera-se com este trabalho um maior incentivo a adesão de mulheres à área de tecnologia.

\section{Introdução}

É comum associar a programação com a invenção do computador, presume-se que programar é escrever um software, porém esse conceito se aplica antes mesmo da criação do computador. Charles Babbage, considerado precursor para a existência do que se conhece hoje como computador devido a criação da máquina analítica, contou com a ajuda de uma mulher, Ada Lovelace, para que sua máquina de fato realizasse seu propósito: resolução de equações e construção de tabelas. Ada ao traduzir os escritos de Babbage contribuiu além do esperado, percebendo que a máquina podia ser programada, enriquecendo o documento com suas próprias anotações entre as quais encontra-se um completo diagrama do cálculo da sequência de Bernoulli. Esse diagrama então é considerado o primeiro programa da história. (SCHWARTZ et al, 2006)

Schwartz (2006) destaca que Ada não foi a única mulher a registrar seu legado na história da programação, outras mulheres fizeram questão de deixar suas contribuições para a tecnologia, como Grace Hopper, Mary Kenneth Keller e as 75 mulheres envolvidas na programação do ENIAC - considerado o primeiro computador. 
Mesmo com tantos nomes femininos, o mesmo não se reflete no cenário atual. Carolina Marins Santos (2018) para o Jornal da Universidade de São Paulo (USP), mostrou que na década de 1970, cerca de 70\% dos alunos do curso de Ciências da Computação, no Instituto de Matemática e Estatística da Universidade de São Paulo (IME-USP), eram mulheres, na turma de 2016 o número chegou apenas a $15 \%$. No Brasil, de acordo com o Censo da Educação Superior de 2016, as mulheres representam apenas $14,1 \%$ dos matriculados no curso de Análise e Desenvolvimento de Sistemas, sendo esse o $16^{\circ}$ maior curso de graduação em número de ingressantes na área de tecnologia (BRASIL, 2018).

Este trabalho tem por objetivo apresentar os resultados de um levantamento e possíveis indicadores de empoderamento feminino extraídos de comunidades tecnológicas de linguagens de programação. Assim, espera-se com este trabalho um maior incentivo a adesão de mulheres à área de tecnologia através desses coletivos.

\section{Empoderamento feminino e suas causas}

O termo empoderamento se refere a uma gama de atividades, da assertividade individual até à resistência, protesto e mobilização coletivas, que questionam as bases das relações de poder. No caso de indivíduos e grupos cujo acesso aos recursos e poder são determinados por classe, casta, etnicidade e gênero, o empoderamento começa quando eles não apenas reconhecem as forças sistêmicas que os oprimem, como também atuam no sentido de mudar as relações de poder existentes. (BATLIWALA, 1994, p. 130 apud SARDENBERG, 2006)

Marinho e Gonçalves (2016) defendem que existe uma estrutura desigual de relações de poder entre homens e mulheres, essas relações abrem a possibilidade de mulheres resistirem e poderem exercer tal poder inalcançável a elas, podendo ser via suporte e conscientização entre seus grupos, sendo no caso da área tecnológica, as comunidades tecnológicas criadas pelas mesmas com o intuito de reunir outros indivíduos do gênero com o interesse em comum no ramo de programação a fim de disseminar conhecimento e fortalecer as mulheres atuantes ou ingressantes na área.

A criação desses grupos para alcance de poder pode ser explicada por Posser e Teixeira (2016) ao identificar os motivos da diferença significativa do número de homens e mulheres no mercado de tecnologia da informação. Os autores, dividindo suas análises em escopos globais e locais, após reafirmar o cenário de discrepância, constaram que as principais causas da redução da presença feminina na área se deve a dois fatores: (1) a ausência de estímulos na infância e/ou juventude que torna a escolha por algum curso correlatado a área mais difícil; e (2) o estereótipo de que a área de tecnologia é masculina, tornando o ingresso mais estigmatizado.

\section{Metodologia}

Para determinação dos possíveis indicadores de empoderamento feminino através de comunidades tecnológicas de linguagens de programação, a metodologia englobou duas etapas: avaliação qualitativa (1) seguida da extração de indicadores, gerando uma avaliação quantitativa (2). Tendo como referência 42 comunidades tecnológicas de linguagens de programação voltadas para o público feminino foi elaborado um questionário a fim de saber o impacto que essas e outras comunidades geraram para as mulheres antes e depois do seu ingresso nessas comunidades. 
Perante isto, várias questões aparecem na tentativa de se identificar os motivos da pouca participação das mulheres nas áreas de tecnologia, as duas principais são:

I. Como você se sentia dentro da área de tecnologia - ou fora - antes de conhecer uma comunidade do gênero?

II. Após você se juntar a uma comunidade, como você se sentiu?

O formulário foi respondido por 124 mulheres, de forma anônima, através da ferramenta Google Forms, o formulário foi disposto no período de 9 a 17 de abril de 2020. Os resultados são apresentados a seguir.

\section{Resultados e discussões}

Após a coleta dos dados foi feita uma avaliação qualitativa das respostas e a segmentação dos principais tópicos antes e depois de participar de uma comunidade, as respostas foram agrupadas por assuntos em comum que as entrevistadas abordaram. $\mathrm{Na}$ sequência, a extração e tabulação quantitativa para cada tópico:

- Isolamento devido ao gênero: "Achava que eu teria que viver trabalhando na área que eu gosto como minoria."

- Estereótipos relacionado aos gêneros: "[...] achava que a área não era pra mim, e que por isso, nem deveria tentar ser da área.".

- Desamparo: "[...] não sabia exatamente como fazer para conseguir crescer na área por ser mulher. eu já via sim mulheres incriveis na área, mas me pareciam inacessiveis.".

- Sexismo: "[...] a voz da mulher é abafada de forma quase invisivel a todos, apenas homens são levados a sério.", "[...] sempre tenho de provar minhas próprias habilidades a todo momento, cobrança que eu não vejo para os homens.".

- Constrangimento: "[...] também não me sentia à vontade para tirar dúvidas, ficava com vergonha por achar que os meninos estavam sempre à frente com relação aos códigos.".

Tabela 1. Assuntos abordados pelas entrevistadas sobre a área de T.I. antes de ingressar em uma comunidade tecnológica.

\begin{tabular}{|l|l|}
\hline Assunto abordado na resposta & Frequência \\
\hline Isolamento devido ao gênero & 86 \\
\hline Estereótipos relacionado aos gêneros & 68 \\
\hline Desamparo & 44 \\
\hline Sexismo & 30 \\
\hline Constrangimento & 21 \\
\hline Outros & 9 \\
\hline
\end{tabular}


As observações desta avaliação indicam que cerca de 92\% das entrevistadas sentiam-se perdidas, inseguras, desconfortáveis por serem mulheres e não enxergarem referências femininas na área de tecnologia, tópicos esses já apontados por Posser e Teixeira (2016) anteriormente. Além disso, apontou que $89 \%$ dessas mulheres não tinham interesse em ingressar na área de tecnologia devido à grande presença masculina e os estereótipos impostos, enfatizando também o sentimento de não pertencimento, incapacidade e medo do julgamento constante.

Com isso, ao analisar os tópicos relacionados ao pós-ingresso a uma comunidade, obteve-se as seguintes respostas, agrupadas por assuntos em comum, que ilustram os conceitos identificados, bem como a Tabela 2 com o quantitativo:

- Representatividade: "Me senti reconfortada em saber que não sou a única a enfrentar o preconceito que ainda existe em ser mulher e trabalhar com TI.", "[...] vendo mulheres incriveis tendo uma carreira de sucesso na área, senti que também poderia chegar tão longe quanto elas. [...]”.

- Acolhimento: "Hoje consigo me sentir forte, apoiar e incentivar outras meninas. [...]”, “[...] sinto que finalmente pertenço a algo e a um grupo onde posso falar como me sinto e sei que serei compreendida.".

- Motivação: "[...] tenho ânimo pra conquistar cada vez mais espaço na área, o sentimento de isolamento não me assombra mais como antes;".

- Autoconfiança: "[...] que eu posso ir além do que só ligar o computador eu posso criar muitas outras coisas.”, “[...] pude perceber que tecnologia é maravilhosa, que tenho talento e com esforço também consigo. [...]”.

- Conhecimento técnico: "Me senti a vontade de compartilhar coisas que eu sei e que eu aprendi.", "Me conecto ao assunto e oportunidades, não tenho medo de fazer perguntas iniciantes sobre alguma linguagem ou framework. [...]".

Tabela 2. Assuntos abordados pelas entrevistadas sobre a área de T.I. pós-ingresso em uma comunidade tecnológica.

\begin{tabular}{|l|l|}
\hline Assunto abordado na resposta & Frequência \\
\hline Representatividade & 91 \\
\hline Acolhimento & 72 \\
\hline Motivação & 32 \\
\hline Autoconfiança & 23 \\
\hline Conhecimento técnico & 16 \\
\hline Outros & 4 \\
\hline
\end{tabular}

Averiguou-se que, após o ingresso em uma comunidade tecnológica, cerca de $96 \%$ das mulheres afirmam se sentirem acolhidas, motivadas e encorajadas a continuarem a seguir na área. Também, constatou-se que $74 \%$ das mulheres 
complementa que o principal motivo de se sentirem bem após o ingresso se dá pela representatividade de ter e poder conhecer outras mulheres na área.

\section{Considerações Finais}

O estudo realizado deu indícios sobre a relevância que as comunidades de Tecnologia podem incentivar a adesão de mulheres à essa área. Percebe-se também que as comunidades podem proporcionar experiências que induzam as mulheres a se sentirem empoderadas em uma área que historicamente, contribuíram para sua consolidação. Além disso, os indicadores sugerem importantes fatores de empoderamento dessas mulheres. Verificou-se que antes de frequentar uma comunidade, as mulheres possuem a impressão que a área de tecnologia não é um ambiente acolhedor para o gênero feminino, devido ao peso do preconceito e estereótipos. Como trabalhos futuros, sugere-se investigações sobre os meios de descoberta de comunidades tecnológicas por mulheres. Além disso, trabalhos que identifiquem formas de melhorar a disseminação dessas comunidades afim de motivar cada vez mais o ingresso feminino na área de tecnologia.

\section{Referências}

BRASIL. Ministério da Educação. Instituto Nacional de Estudos e Pesquisas Educacionais (Inep). Censo da Educação Superior 2016: Resumo Técnico. Brasília: MEC, 2018.

MARINHO, P. A. S.; GONÇALVES, H. B. Práticas de empoderamento feminino na América Latina. Colômbia: Revista de Estudios Sociales, 2016.

SANTOS, C. M. Por que as mulheres "desapareceram" dos cursos de computação? Disponível em: <https://jornal.usp.br/universidade/por-que-as-mulheres-desapareceramdos-cursos-de-computacao/>. São Paulo, Universidade de São Paulo, 2018. Acesso em 18 abr 2020.

SARDENBERG, C. M. Conceituando "Empoderamento" na Perspectiva Feminista. Salvador: Universidade Federal da Bahia, 2006.

SCHWARTZ, J., et al. Mulheres na informática: quais foram as pioneiras? Campinas: Universidade Estadual de Campinas, Núcleo de Estudos de Gênero - Pagu, 2006.

POSSER, C.; TEIXEIRA, A. C. Mulheres que aprendem informática: Um estudo de gênero na área de TI. Uberlândia: V Congresso Brasileiro de Informática na Educação, 2016. 